\title{
An Unparalleled Salvage Undertaking
}

\author{
Floating a Wrecked Vessel on Her Side \\ By Robert G. Skerrett
}

THE most ambitious salvage undertaking yet essayed 1 is that now in progress in an effort to refloat the sunken freighter "Washingtonian," formerly of the American-Hawaiian Line. We say formerly, because all claims to the vessel have lately been renounced by her quondam owners in the belief that the craft is a hopeless loss. There is nothing in the annals of successful marine wrecking ventures that reasonably approximates the salvage problem presented by the "Washingtonian," lying as she does in the neighborhood of 15 miles off shore in the open sea and 90 feet down below the surface at mean low tide. Nevertheless, engineering courage has not been daunted, and men of skill are giving their best efforts to a technical gamble that will make salvage history if success reward their labors.

On the 26th of January, 1915, the "Washingtonian," laden with sugar from Hawaii, was nearing the Capes of the Delaware bound for Philadelphia, when she was struck by a big five-masted schooner, during a heavy fog, and sent to the bottom in the brief span of 10 minutes. The invading sea saturated the upper mass of the sugar,

shifted the ship's

center of gravity, and caused her to turn turtle. As subsequently de termined by Government divers, the freighter . settled upon the seabed, over on her starboard side, and with a heel of substantially $75 \mathrm{de}-$ grees. This posture, in itself, would have added to the difficulties to the diting of re vessel had she gone down in sheltered waters; and salvors with the usual equipment would probably have hesitated a long time before trying to raise the craft from rals of 90 feet. The accepted order of procedure, in substantially landlocked a ters, locked w a ters would have involved the use of pontoons to get the vessel on an even keel and then to raise her so that she could be pumped out. Considering the size of slder "Washingtonian," a ship nearly 408 feet long and of 6,650 gross tons, it was realized by the would-be salv ors that her bulk and weight stood in the way of utilizing pontoons. This was especially evident in view of the depth in of submergence, difficulty of making properly fast to the vessel, her position seaward, and the time that would be required to get her up and to move he up and to moreward.

It was apparent to the engineers concerned that the "Washingtonian," to be successfully salved, would have to be brought$$
\text { the chance posture of the ship has proved a possible }
$$

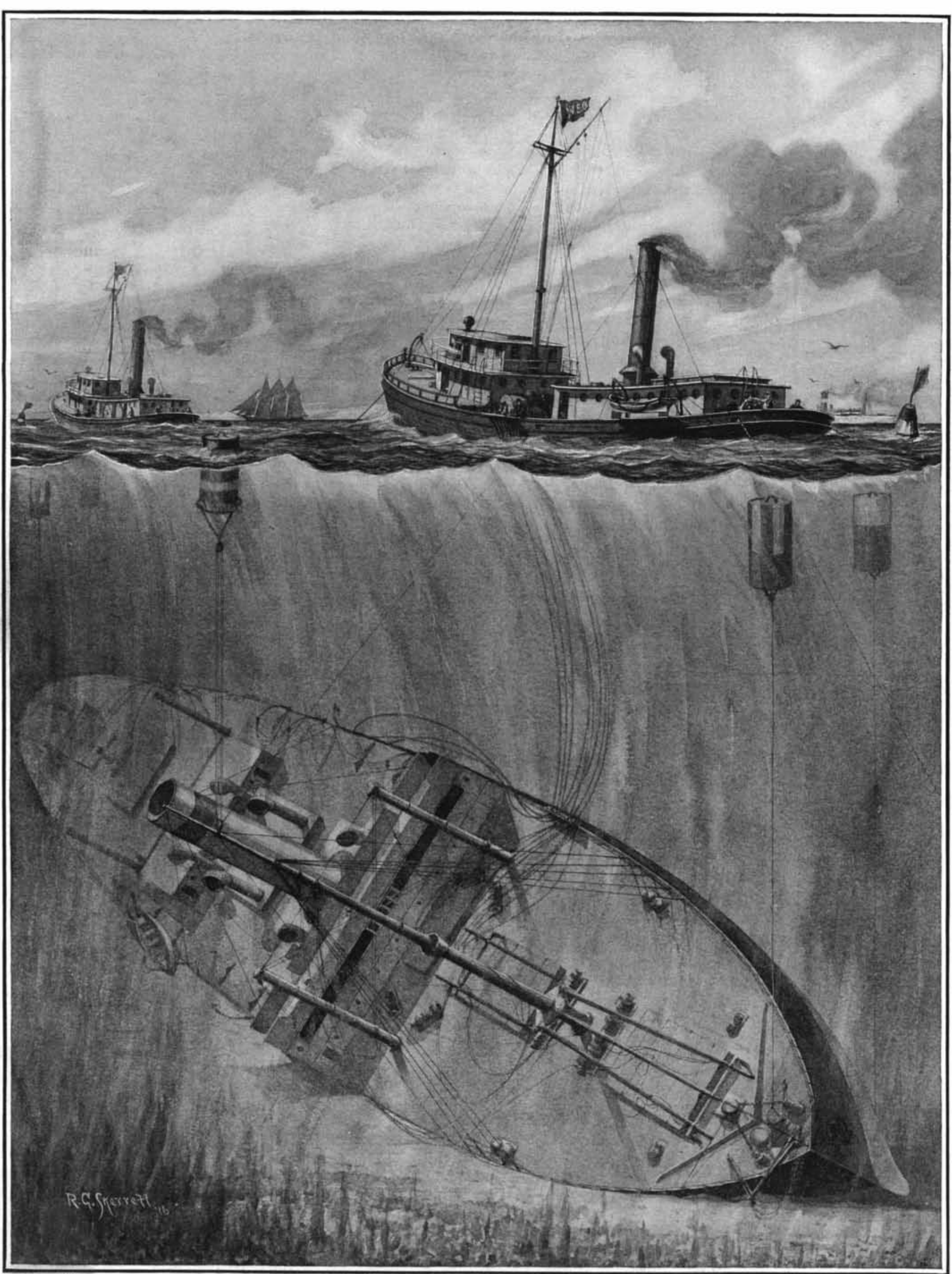

The "Washingtonian" lying at an angle of seventy-five degrees aid and not an added handicap in salvage operation. The "Washingtonian" is built upon what is technically known as the Isherwood system of construction, and because of this she is exceptionally strong in some particulars and able to withstand the bursting force of pent-up air between decks when that air is pocketed so as to bear against only limited areas of the decks. This can best be realized by reference to the accompanying diagram. But first, let us keep in mind that the ship has vents extending to her upper or shelter deck, and it is to these pipes that hose will be attached reaching thence to the surface craft and their air supplies. These vents lead directly to the several compartments, interdeck spaces, and the various tanks. Therefore, it is entirely practicable to distribute the air to the particular points desired.

The vessel's posture on the seabed is called her "first position," and the object of the salvors is to bring her to the second position with her mast horiside uppermost he purpose of this is to increase the initial air pocket so that it will be nearly rectangular and, therefore, capable of holding a larger measure of buoyancy. At the same time, it is necessary to control the craft so that she shall not turn bottom upward. How will all this be done? To begin, air will first be blown into the double bot to m tanks and into what is known as the deep tank-the latter being situated in the hold of the freighter and just forward of the boiler space. It was used as a stowage place for fuel oil. With air in her double bottom and deep tank, there will be enough buoyancy to break the ship away from contact with the seabed and possibly to start a turning movement tending to bring her botton uppermost. This, however, will hardly suffice to refloat the craft, and therefore air will have to be admitted to the space be tween the decks and the upturned side -the lower limit being the top edge of the cargo hatch. The vessel will be prevented from turning bottomside up by an ingenious expedient.

The "Washingtonian" lost her mainmast at the time of the collision but her foremast is still standing. $\mathrm{By}$ an adjustable purchase, the outer end of this mast will be buoyed to a control tank having a total lifting capacity of some scores of tons. The mast will thus form a great lever. The tank will serve to hold the mast up at the pivotal point 
of attachment, and in this way arrest any excessive upsetting motion on the part of the craft's body. This control is made more positive by leading the end of the control purchase to a winch aboard one of the salvage steamers. In this way the mast can be raised or lowered at will. At each end of the ship are two marker caissons, moored just below the surface. As the freighter starts to rise these caissons will indicate the degree of the movement and whether the bow or the stern or the keel tends to come uppermost. It is very important that the refloating be under nice control and that the vessel be brought up with her port side just level with the surface.

The air connections from both salvage steamers are led down to two widely separated stations at which are attached two frames with intermediate connections. That is to say, the air pipes from the surface will be joined to these connections at the rail as are also the second sections of the air feeds leading thence to the deck vents. The purpose of this is to simplify the task of insulation and to prevent any mistake on the part of the divers. There are two sizes of hose and the connecting lengths leading from the frames to the deck taps are just long enough in each case to reach a certain point, and where two lines are of the same length they are of different calibers and, therefore, cannot be improperly attached. The divers will first make the connections between the rail frames and the vents, and with these in place then the sections of hose leading to the surface vessels will be joined. There are duplicate frames on the salvage steamers, and in this manner it will be possible to know just where the air is going when it is sent down into the "Washingtonian."

As soon as she is brought to the surface, the "Washingtonian" will be towed as speedily as possible to the sheltered and shallow waters inside of the Delaware Capes where she will be grounded. Her righting will then be a comparatively easy matter. With this done the freighter will be pumped out and refloated and her wound repaired temporarily. Pumping out will, of course, admit air between decks while there is water above them, but as the decks are designed to withstand a heavy load, though not able to resist a bursting pressure from within, no risk will be run in this operation. Of course, this procedure could not be adopted with the vessel lying 90 feet down, because then the overload of water would immediately crush the deck inward.

The situation that has inspired the present salvage exploit is directly due to the war: the scarcity of ships and the high freight rates. When the "Washingtonian" was sunk, independently of her cargo, the vessel was valued at substantially $\$ 750$, 000. To-day, if afloat, and ready for serv ice, she would easily bring $\$ 2,000,000$ ? This is inducement enough to attract the present salvors and to win the powerful coöperation of the capital involved. As an engineering feat it is well worth the effort, and even if the result be unsuccessful still there will be a technical gain and the art will be much richer for the rare experience.

\section{Logistics}

By George C. Thorpe, Major, M. C.

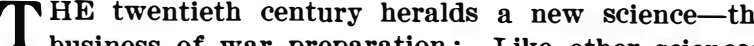
its elements are not new; they have made a nearscience for a hundred years or more, but only now is the vast importance of their unification-one might almost say their imperialization-becoming a reality.

Briefiy to indicate its place, we must recall that wa involves three divisions of labor: Strategy, Tactics, and Logistics. The first is the planning department; the second the objective execution; the third the business department.

The business of warfare provides the means of fight ing; hence it operates from the beginning to the end; during peace as well as in war; from the very formatio of the nation's fighting forces to-the time when there shall be no war. It provides the uniform for the newfound recruit, builds the ship that will go into the fleet maintains all the fighting forces throughout their existence, takes care of the wounded during battle, and clears the battlefield of dead and prisoners at the end. In short, it is all there is of wdy except the plans of Strategy and the actual employtitent of Tactics.

One might ask why this should be reckoned a modern science. There have been only about 250 years of peace during the past thirty-four centuries, and certainly every one of the eight thousand wars that have been fought during that period have required the means of fighting. Why, then, has not logistics been always operative?

Its elements have been employed from first to last, and in a steadily incrensing extent; the progress of war has been almost entirely the progress of logistics. The earliest battles involved little else than tactics not being planned in advance, there was no strategy; as the flght was on a small scale, it was soon over, and so did not require measures for supply, transportation, elaborate communications, etc that we now classify as logistical features. When, in the early stages of history, strategy began to find its place in warfare, operations became more complicated; then the issue depended upon the results of more than one battle; the contest was prolonged; arrangements had to be made for the food supply. Furthermore, strategy introduced strategems which involved preparation of traps, hiding-places, some arrangement for communications and for getting information; thus logistics get its first importance from strategy. The modernization of the elements of logistics consists in their unification into a science.

Such unification is not merely an academic consideration, but a matter of great practical importance. Omission in this respect was responsible for the failure orate preparations; the French armies set out with generous provision for everything in the shape of means; almost too much transportation, possibly too large staffs, and at the front troops at times had such quantities of food that they trampled it under foot But wagons were used for improper purposes; wagon and river-boats were not brought to the proper places in time to distribute food supplies; means were not prearranged for reducing grains to flour; the subsistence department did not confer with the engineers to insure the preparation of roads for the supply trains of Napoleon's Russian campaign. He had made elab-

development of situations and means of meeting them, to permit anything like accurate estimates of requirements being made in advance. But timely estimates, based on the best data obtainable, surfly promise better preparation than no scientific estimate at all. The business outlook of a possible or probable war can be viewed correctly only by a comprehensive estimate from all angles. There is the same utility in coördinating the elements of logistics under one head as there is in having a board of directors to estimate the business situations of a corporation.

\section{The Current Supplement}

A PARTICULARLY interesting article that will be A found in the current issue of the Scientific American Supplement, No. 2124, for September 16, is The Metabolism of Insects, which tells of the successive changes undergone during their post-embrionic lives. An absolute essential to both attack and defense in the war methods of to-day, is the heavy artillery that is being used extensively by both sides. The Big Guns of the War summarizes many facts concerning these surprising weapons, and is accompanied by a number of illustrations. Magic Pictures is another illustrated article that describes a number of easily performed and attractive experiments that will furnish amusement for a winter evening. The explanatory photographs are excellent. The Decay of Mctals discusses certain changes in character that are liable to occur in sereral materials. The paper on Internal Combustion Engine Cycles is concluded. The Pallograph describes an in genious instrument that records both horizontal and vertical vibrations, and which is of great value in inrestigations of many kinds, particularly those relating to ships. Unstable States in Arc and Glow Lamps discusses a number of interesting phenomenon in a concise and readable manner. The History of the Safety Lamp sums up the efforts of a hundred years, and describes many of the devices that have been introduced to supply light to miners. There are also a number of shorter papers.

\section{Cement Posts for Austrian Hop Gardens}

F XPeriments now being carried on $\mathrm{C}_{\text {in Germany, if successful, may create }}$ a market in the Carlsbad district for an American product. It is proposed to use cement posts in hop gardens for carrying the wires on which the vines grow. Wooden (pine or fir) polès are now used. They are about 8 feet. long and cost 80 cents each. They are treated with a preservative to prevent rot, and their average life is 12 to 15 years.

If these experiments are successful, there will be a field in the Carlsbad district for the placing of cement machines. Its extent is indicated in the fact that in normal times, in the Saaz district, there is a hop acreage of 30,000 , and it is calculated that with the present system of wooden poles, 210 poles are needed to the acre. With the use of concrete probably n" will be refloated without righting her until she has wooden poles, 210 por
been towed into shallow water

there was not such coördination between the tactical staffs and hospital corps as to obtain proper attention to the wounded after battle; the relation between the communicating it in usable form to the commander was not so established that the commander could take advantage of contacts with the enemy. The history of this campaign shows that, while Napoleon's strategy and tactics were excellent, there was no coördination between the functions of providing the means of fighting. The situation was reversed with the Russians: they had little or no plan, but their leader, Barclay de Tolly, had genius for organization.

To-day, either before or at the outbreak of war, the General Staff outlines the probabilities of the campaign in an "estimate of the situation," which is the basis for the issuance of orders. These orders, in turn, are notification to all the departments interested in providing means of what will be expected of them; in order to respond efficiently to this responsibility, without duplication, waste or omission, they must jointly estimate the business part of the situation; the division of labor will be determined, in the main, by the organization that would have been made previously but even so there is much call for conference and coördination in the practical execution. For instance, trans portation department cannot know how much transportation will be required until several of the other departments, such as subsistence, hospital corps, and supply departments in general, are heard from. On the other hand, if transportation facilities are limited, the supply departments must arrange their shipments accordingly, providing what shall go first, etc.

No two wars have been sufficiently similar, in the not so many poles would be needed.
The wire now used costs 8.7 cents per pound, a 24 per cent increase over the price before the war. It is estimated that the poles and wires installed in the hop gardens of the Saaz district represent an investment of more than $\$ 3,000,000$.

\section{Use of Hypochlorite of Magnesium as an Antiseptic}

\section{R EGARDING the use of hypochlorite of magnesium}

$\mathbf{R}_{\text {as an antiseptic for surgical use, it appears that }}$ since the war the value of hypochlorite compounds i being fully recognized, and they are now taking the place which they deserve on account of their well marked antiseptic properties. The principal salt used for this purpose is hypochlorite of sodium, but as its solutions are somewhat caustic on account of their alkaline nature, it would be an advantage, as Dr. Chas Mayer points out, to replace this by the hypochlorit tion such as is well adapted for the treatment of wounds, by mixing two separate solutions; first, a solution of 100 parts by weight of chloride of calcium in 2,000 parts water, and second, a solution of 190 parts sulphate of magnesium in 2,000 parts water. Mix th solutions and allow the precipitate to settle, then decant off the clear liquid, and this latter is then ready to be used as an antiseptic solution for surgical purposes. It has the advantage of not being at all caustic and so can be employed in a rery concentrated solution. We would remark that this solution lias now entered the trade here, and surgeons express themselves as very well satisfied with it, especially as the magnesium salt is found to be favorable to the defense and repair of infected wounds. of magnesium. This salt is very easy to obtain in solu- 